\title{
Pollutant loads of surface runoff in Wuhan City Zoo, an urban tourist area
}

\author{
ZHAO Jian-wei ${ }^{1,2}$, SHAN Bao-qing ${ }^{1, *}$, YIN Cheng-qing ${ }^{1}$ \\ 1. State Key Laboratory of Environmental Aquatic Chemistry, Research Center for Eco-Environmental Sciences, \\ Chinese Academy of Sciences, Beijing 100085, China. E-mail: jwzhao2@163.com \\ 2. Graduate University of Chinese Academy of Sciences, Beijing 100049, China
}

Received 31 March 2006; revised 25 April 2006; accepted 5 June 2006

\begin{abstract}
The pollutant loads of surface runoff in an urban tourist area have been investigated for two years in the Wuhan City Zoo, China. Eight sampling sites, including two woodlands, three animal yards, two roofs and one road, were selected for sampling and study. The results indicate that pollutants ranked in a predictable order of decreasing load (e.g. animal yard $>$ roof $>$ woodland $>$ road), with animal yards acting as the key pollution source in the zoo. Pollutants were transported mainly by particulate form in runoff. Particulate nitrogen and particulate phosphorous accounted on average for $61 \%, 78 \%$ of total pollutant, respectively, over 13 monitored rainfall events. These results indicate the treatment practices should be implemented to improve particulate nutrient removal. Analysis of the $M(V)$ curve indicate that no first flush effect existed in the surface runoff from pervious areas (e.g. woodland, animal ground yard), whereas a first flush effect was evident in runoff from impervious surfaces (e.g. animal cement yard, roof, road).
\end{abstract}

Key words: surface runoff; stormwater pollution; urban tourist area; impervious/pervious surface; $M(V)$ curve

\section{Introduction}

Urban runoff is an important source of pollution responsible for impairing water quality (USEPA, 2002). Urban runoff carries high pollutant loads, including sediment, nutrients, heavy metals, oils and hydrocarbons, and oxygen-demanding substances. Further, urban surfaces are characterized by a high proportion of imperviousness, resulting in flashier hydrographs with higher, earlier peaks (Wanielista and Yousef, 1993; Gupta and Saul, 1996).

Several studies have reported surface runoff pollution in urban-residential and industrial dominated (GromaireMertz et al., 1999; Lee and Bang, 2000; Choe et al., 2002; He et al., 2005). However, there are very few studies reporting water quality and quantity characterization of urban zoos. In urban zoos, the ratio of pervious surface (value for urban zoo ratio) is larger than in urban residential (value for urban residential ratio) and industrial areas (value for industrial ratio), reflecting the higher vegetation coverage in zoos. The drainage system in zoos is also distinct from other urban areas because it is shallower than that of other areas. These hydrologic features of zoos make the investigation of the pollution process and runoff characteristics important for determining appropriate strategies to control surface pollutants in these areas.

Project supported by the National Hi-Tech Research and Development Program (863) of China (No. 2002AA601022). *Corresponding author. E-mail: bqshan@rcees.ac.cn.

\section{Methods}

\subsection{Study sites}

The study was conducted from May 2004 to August 2005 in the Wuhan City Zoo, China. Wuhan City is situated in a subtropical area of China, with continent monsoon climate that generates intensive rainfalls in the summer. The mean annual temperature is $15.9^{\circ} \mathrm{C}$ and the annual precipitation is approximately $1300 \mathrm{~mm}$, two-thirds of which falls from April to August.

The experimental catchment in the Wuhan City Zoo drains $26 \mathrm{hm}^{2}$ (Fig.1) of (sandy, silty, clayey) soils. The main landuses within the catchment include woodland (WD), animal yard (AY), roof (RF) and road (RD) in the zoo. The animal concrete yard, roof and road surfaces are all essentially impervious and account for $24 \%$ of the entire catchment. The animal ground yard, woodland surfaces are pervious. The pervious surface is divided into many fragments by animal yard, road, and buildings.

Eight sampling sites, including all main landuses, were selected for investigation (Table 1). The main pollutants in the runoff from animal yards are animal waste. Despite a daily cleaning schedule, some pollutants remain available for transport by surface runoff. All roads in the zoo are cleaned thoroughly once a day.

\subsection{Experimental methods}

Runoff samples were taken manually. All water samples were collected in plastic bottles, beginning at the initiation 
Table 1 Summary of characteristics of studied catchments at different sites in Wuhan City Zoo (see Fig.1)

\begin{tabular}{|c|c|c|c|c|c|c|c|}
\hline \multirow[t]{2}{*}{ Sampling site } & \multirow[t]{2}{*}{ Land use } & \multirow[t]{2}{*}{ Area $\left(\mathrm{m}^{2}\right)$} & \multirow{2}{*}{$\begin{array}{l}\text { Percent of impervious } \\
\text { area }(\%)\end{array}$} & \multirow[t]{2}{*}{ Type of surface } & \multirow[t]{2}{*}{ Land slope (\%) } & \multicolumn{2}{|c|}{ Percent of vegetation $(\%)$} \\
\hline & & & & & & Arbor & Grass \\
\hline WD1 & Woodland & 4085 & 11.8 & Pervious & 8.3 & 73 & 11 \\
\hline WD2 & Woodland & 5167 & 14.1 & Pervious & 4.4 & 76 & 68 \\
\hline AY1 & Animal ground yard & 220 & 0 & Pervious & 0 & 9 & - \\
\hline AY2 & Animal ground yard & 808 & 0 & Pervious & 9.3 & 30 & - \\
\hline AY3 & Animal cement yard & 1120 & 100 & Impervious & 3.2 & - & - \\
\hline RF1 & Roof & 27 & 100 & Impervious & 10.6 & 22 & - \\
\hline RF2 & Roof & 15 & 100 & Impervious & 0 & 51 & - \\
\hline $\mathrm{RD}$ & Road & 20 & 100 & Impervious & 5.1 & 43 & - \\
\hline
\end{tabular}

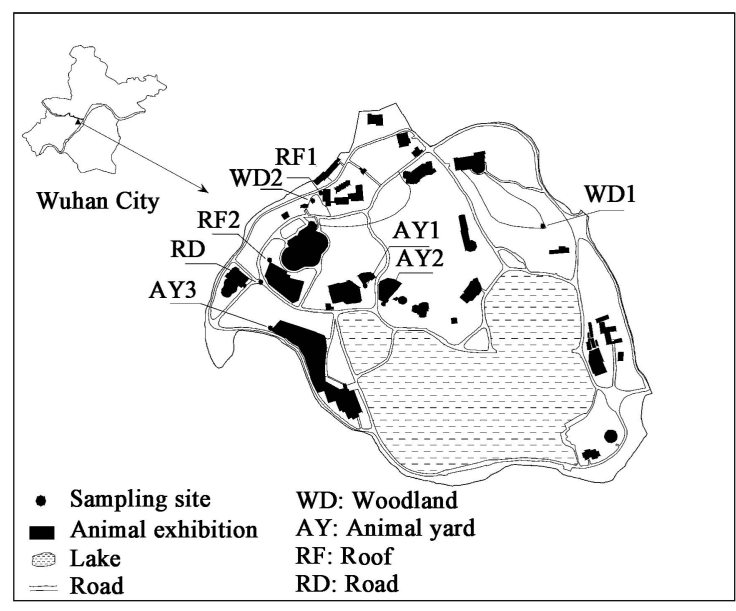

Fig. 1 Map of experimental area and location of sampling sites.

of the runoff and ending when the runoff ceased. Samples were collected at the outlet of each site with an interval of $5 \mathrm{~min}$ in the first $30 \mathrm{~min}$ followed by $10 \mathrm{~min}$ intervals until runoff ceased. Time of sampling and runoff volume were recorded simultaneously. Runoff volume was measured using calibrated polythene barrel with $20 \mathrm{~L}$ for higher volumes and $5 \mathrm{~L}$ for smaller volumes. Rainfall intensity data was recorded by an automated gauge in the zoo. The rainfall patterns are summarized in Table 2.

Suspended solids (SS) and chemical oxygen demand (COD) were measured according to Standard Methods of APHA (1998). All the samples were filtrated with 0.45 $\mu \mathrm{m}$ millipore filter. The filtrate was used for measuring constituents of dissolved nitrogen (DN) and dissolved phosphorus (DP). All the filtered and unfiltered water samples were digested simultaneously for determination of nitrogen and phosphorus concentrations (Ebina et al., 1983). The particulate nitrogen (PN) and particulate phosphorus (PP) concentrations were determined as the difference between total nitrogen (TN) and $\mathrm{DN}$, and that between total phosphorus (TP) and DP, respectively.

\subsection{Data analyses}

Event mean concentrations (EMC), a single index to characterize pollutant in runoff (Novotny and Olem, 1994; Sansalone and Buchberger, 1997), was used to estimate pollutant loads in the runoff from eight sampling sites. The EMC is a flow-weighted average of constituent concentration, and can be represented as

$\mathrm{EMC}=\frac{\int_{0}^{t} C(t) \times Q(t) \mathrm{d} t}{\int_{0}^{t} Q(t) \mathrm{d} t}$

where, EMC is the event mean concentrations $(\mathrm{mg} / \mathrm{L}) ; C(t)$ is the time variable concentration $(\mathrm{mg} / \mathrm{L}) ; Q(t)$ is the runoff flow rate discharged at time $t\left(\mathrm{~m}^{3} / \mathrm{min}\right)$.

The export of pollutants was assessed by the unit pollutant loading rate. The following equation can be used to calculate this index (Lee and Bang, 2000):

$L=K C_{i} \times \Delta Q_{i} \times \Delta t_{i} \times R /\left(\sum \Delta t_{i} \times A_{i} \times I_{i}\right)$

where, $L$ is the unit pollutant loading rate $\left(\mathrm{kg} /\left(\mathrm{hm}^{2} \cdot \mathrm{a}\right)\right.$; $K$ is the conversion constant $\left(10^{-3}\right) ; C_{i}$ is the average concentration of the composite sample during the $\sum \Delta t_{i}$ interval $(\mathrm{mg} / \mathrm{L}) ; \Delta Q_{i}$ is the runoff in $\Delta t_{i}$ interval $\left(\mathrm{m}^{3} / \mathrm{h}\right)$; $\Delta t_{i}$ is the sampling time interval (h); $\sum \Delta t_{i}$ is the rainfall

Table 2 Patterns of rainfall event sampled

\begin{tabular}{|c|c|c|c|c|c|}
\hline Date & $\begin{array}{l}\text { Rainfall depth } \\
\qquad(P, \mathrm{~mm})\end{array}$ & $\begin{array}{l}\text { Rainfall duration } \\
\qquad\left(T_{\mathrm{r}}, \mathrm{h}\right)\end{array}$ & $\begin{array}{l}\text { Ave. rainfall intensity } \\
\qquad(I, \mathrm{~mm} / \mathrm{h})\end{array}$ & $\begin{array}{c}\text { Max. rainfall } \\
\text { intensity }\left(I_{\max }, \mathrm{mm} / \mathrm{h}\right)\end{array}$ & $\begin{array}{l}\text { Days since last } \\
\text { storm (d) }\end{array}$ \\
\hline 11 May 2004 & 13.6 & 3.1 & 4.4 & 22.8 & 3 \\
\hline 14 June 2004 & 20.1 & 3.6 & 5.6 & 33.6 & 10 \\
\hline 18 June 2004 & 12.3 & 3.1 & 4.0 & 13.2 & 4 \\
\hline 23 June 2004 & 55.3 & 3.8 & 14.6 & 69.6 & 5 \\
\hline 14 Aug. 2004 & 78 & 4.2 & 18.6 & 66 & 3 \\
\hline 8 Apr. 2005 & 18.8 & 1.8 & 10.4 & 40.8 & 52 \\
\hline 1 May 2005 & 10.5 & 2.3 & 4.6 & 31.2 & 15 \\
\hline 17 May 2005 & 32.0 & 2.5 & 12.8 & 32.4 & 3 \\
\hline 10 June 2005 & 35.0 & 3.1 & 11.3 & 40.8 & 23 \\
\hline 26 June 2005 & 78.0 & 7.9 & 9.9 & 46.8 & 15 \\
\hline 10 July 2005 & 30.1 & 4.0 & 7.5 & 54.0 & 13 \\
\hline 22 July 2005 & 27.0 & 1.2 & 22.5 & 82.8 & 12 \\
\hline 3 Aug. 2005 & 41.3 & 4.8 & 8.6 & 45.6 & 8 \\
\hline
\end{tabular}


duration (h); $R$ is the annual total rainfall intensity (mm/a); $A_{i}$ is the watershed area $\left(\mathrm{hm}^{2}\right) ; I_{i}$ is the rainfall intensity $(\mathrm{mm} / \mathrm{h})$.

First flush effect is a common phenomenon in urban runoff pollution (Gupta and Saul, 1996; Lee and Bang, 2000). To evaluate if the first flush phenomenon was exhibited at these sites, $M(V)$ curves were developed. The following $M(V)$ curve can be drawn (Deletic, 1998):

$M(V)=\frac{\int_{0}^{t} C(t) \times Q(t) \mathrm{d} t}{\int_{0}^{T_{\text {run }}} C(t) \times Q(t) \mathrm{d} t}$

where, $C(t)$ is the time variable concentration $(\mathrm{mg} / \mathrm{L}) ; Q(t)$ is the runoff rate $\left(\mathrm{m}^{3} / \mathrm{min}\right) ; t$ is the time elapsed from the start of the event (min); $T_{\text {run }}$ is the duration of runoff (min).

\section{Results and discussion}

\subsection{Effects of land surface properties on the pollution process}

Pollutant loads were largely influenced by the activities and surfaces of the sites. Fig.2a illustrates that pollutant concentrations in the impervious surface runoff were high only at an initial stage and decreased gradually with the rainfall duration. However, pollutant concentration in pervious surface runoff had a positive relation to flow rate and rainfall intensity, as shown in Fig. $2 b$.

Pollutant concentration of runoff from impervious surface quickly decreased after the peak value appeared.
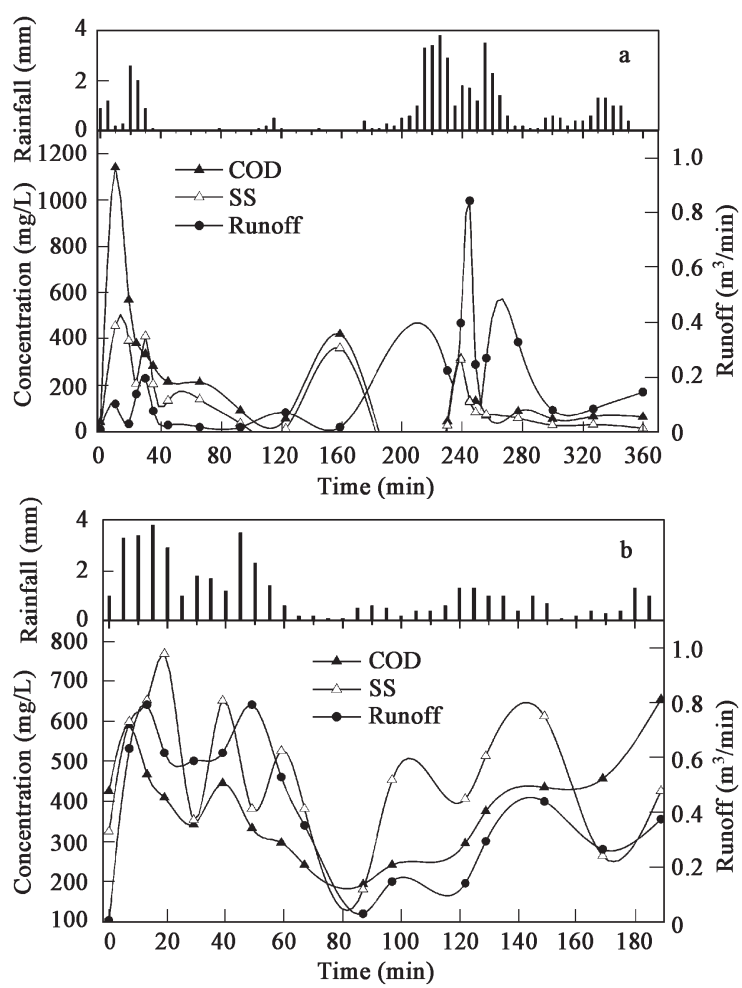

Fig. 2 Typical hydrographs and pollutographs for urban tourist area. (a) AY3, June 26, 2005 (impervious surface runoff); (b) WD1, June 26, 2005 (pervious surface runoff).
This pollution process is similar to the process occurring in other urban watershed with a high impervious ratio (Characklis and Wiesner, 1997). In contrast pollutant concentration of runoff from pervious surface increased with rainfall density increasing in the zoo. This pollution process is similar to that of agriculture area (Fraser et al., 1999; Hammad et al., 2006), because the removal of pollutants from pervious surface depends heavily on the rainfall pattern (Novotny and Olem, 1994). The primary differences in mechanism regulating pollutant concentrations in impervious and pervious surfaces are in the quantity of pollutant in surface and capability of rain to erode the soil surface. High volumes of runoff are generated rapidly over impervious surfaces because precipitation can not infiltrate into soil. Pollutants that have built up on this surface are easily washed off by runoff during the rising limb of the hydrograph. In contrast, pervious surface can be penetrated by water more easily so that only rainfall with high intensity can form sufficient runoff to remove pollutants. Furthermore, pervious surfaces at these sites are composed of soil particles that act as pollutant sources by releasing stored pollutants.

\subsection{Pollutant load from different landuses}

Animal yards were the heaviest pollution sources in the zoo because of animal breeding. The highest pollutant concentrations were measured at the animal yard runoff in all 13 rainfall events (Table 3 ). The analyses indicate that the mass loading rate was in the following order: animal yard $>$ roof $>$ woodland $>$ road (Table 4 ).

The pollutant concentration of roof runoff in the zoo is higher than the concentrations at roofs in other urban areas (Gromaire-Mertz et al., 1999). Accumulated vegetation on the roofs is suspected as the source of pollutants on the roofs at our study sites. Vehicles are prohibited in the zoo and road management is good. Consequently, the runoff pollution from the roads was the lowest in that of all the sampling sites. Woodland with less grass growth (WD1) had a higher pollutant export than the one with more grass coverage (WD2).

\subsection{Pollutant form in the runoff}

Nitrogen and phosphorus were predominantly in particulate form in the runoff of Wuhan City Zoo (Fig.3). PN

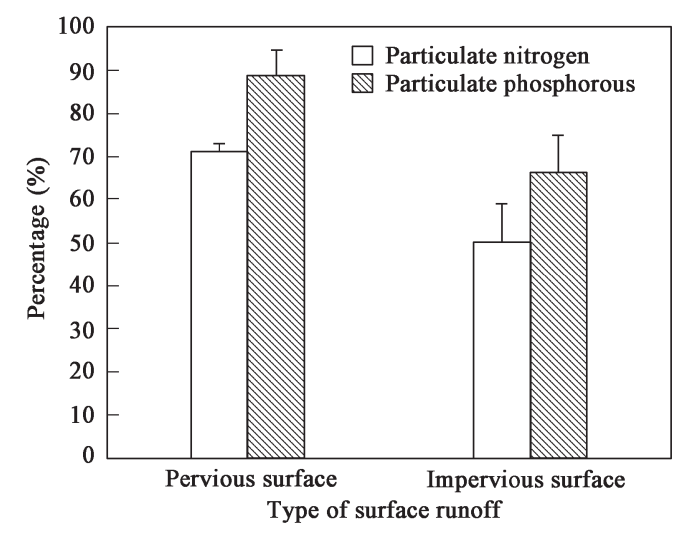

Fig. 3 Percentage of particulate substance in total substance. 
Table 3 EMC (mean \pm standard deviation) for stormwater runoff $(\mathrm{mg} / \mathrm{L})$

\begin{tabular}{llllll}
\hline Site & TN & DN & TP & DP & COD \\
\hline WD1 & $12.8 \pm 3.6$ & $2.62 \pm 2.43$ & $3.71 \pm 2.19$ & $0.23 \pm 0.41$ & $315 \pm 97$ \\
WD2 & $10.0 \pm 5.7$ & $1.83 \pm 1.15$ & $1.84 \pm 0.63$ & $0.11 \pm 0.04$ & $128 \pm 57$ \\
AY1 & $12.5 \pm 4.1$ & $4.06 \pm 1.74$ & $4.25 \pm 1.01$ & $0.30 \pm 0.27$ & $308 \pm 111$ \\
AY2 & $29.5 \pm 4.8$ & $8.37 \pm 4.47$ & $4.75 \pm 0.99$ & $0.32 \pm 0.2$ & $785 \pm 316$ \\
AY3 & $12.5 \pm 5.5$ & $7.58 \pm 2.38$ & $2.11 \pm 0.73$ & $1.10 \pm 0.41$ & $147 \pm 106$ \\
RF1 & $6.4 \pm 4.7$ & $3.07 \pm 0.7$ & $0.67 \pm 0.77$ & $0.09 \pm 0.04$ & $48 \pm 16$ \\
RF2 & $10.4 \pm 2.6$ & $4.39 \pm 2.24$ & $0.93 \pm 0.17$ & $0.33 \pm 0.24$ & $110 \pm 49$ \\
RD & $4.7 \pm 3.1$ & $2.14 \pm 1.14$ & $0.41 \pm 0.09$ & $0.10 \pm 0.05$ & $90 \pm 37$ \\
\hline
\end{tabular}

Table 4 Unit pollutant loading rates for stormwater runoff $\left(\mathrm{kg} /\left(\mathrm{hm}^{2} \cdot \mathrm{a}\right)\right)$

\begin{tabular}{|c|c|c|c|c|c|c|}
\hline Site & $\mathrm{TN}$ & $\mathrm{DN}$ & $\mathrm{TP}$ & DP & COD & SS \\
\hline WD1 & 38.3 & 7.8 & 11.1 & 1.59 & 941 & 2576 \\
\hline WD2 & 19.4 & 3.6 & 3.6 & 0.22 & 250 & 2309 \\
\hline Woodland average & 28.9 & 5.7 & 7.3 & 0.91 & 596 & 2443 \\
\hline AY1 & 87.9 & 28.5 & 33.3 & 2.11 & 2164 & 6215 \\
\hline AY2 & 61.4 & 17.4 & 8.8 & 0.67 & 1632 & 5081 \\
\hline AY3 & 140.2 & 84.7 & 23.6 & 12.25 & 1647 & 2577 \\
\hline Animal yard average & 96.5 & 43.5 & 21.9 & 5.01 & 1814 & 4624 \\
\hline $\mathrm{RF} 1$ & 68.5 & 33.1 & 7.2 & 0.94 & 516 & 668 \\
\hline RF2 & 107.9 & 45.7 & 9.7 & 3.48 & 1144 & 772 \\
\hline Roof average & 88.2 & 39.4 & 8.5 & 2.21 & 830 & 720 \\
\hline $\mathrm{RD}$ & 51.5 & 23.7 & 4.5 & 1.12 & 996 & 622 \\
\hline Entire average & $71.9(39.0)^{*}$ & $30.6(25.7)$ & $12.7(10.4)$ & $2.80(3.95)$ & $1161(631)$ & $2603(2080)$ \\
\hline
\end{tabular}

*Standard deviation.
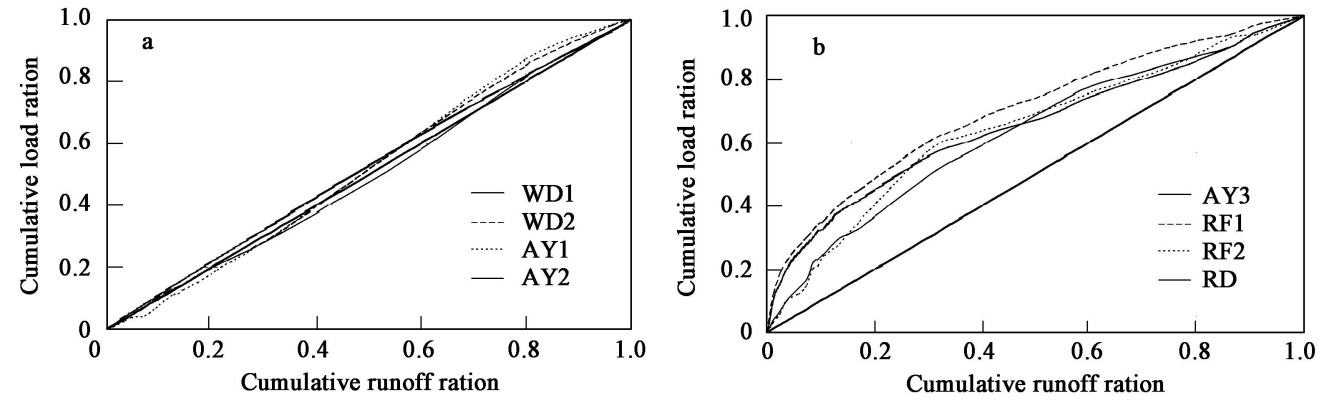

Fig. 4 Cumulative curves of suspended solids (SS) in pervious (a) and impervious (b) surface runoff at four sites in Wuhan City Zoo (see Fig.1).

and PP accounted for $71 \%$ and $89 \%$ of the TN and TP in runoff from pervious surface, $50 \%$ and $66 \%$ in runoff from impervious surface.

Some studies indicated that DN is the main form of $\mathrm{N}$ in urban runoff. Uunk and Ven (1987) reported that PN was below $33 \%$ of the TN in urban runoff, while Taylor et al. (2005) reported that PN accounted for only around $20 \%$ of the total in urban runoff. This study found $\mathrm{PN}$ to be higher in comparison with these studies, with a mean of $61 \%$ PN for all sampling sites. The portion of PP in this study was $78 \%$ and it is similar to the result of US EPA's survey in which PP accounted for $70 \%$ in nationwide urban runoff (Smullen et al., 1999). Because particulate nutrient dominates runoff in the zoo, it is suggested that runoff treatment practices should be designed to improve retention of particulates removal. Wet detention pond, infiltration basin and constructed wetland with good performance on particulate removal may be perfect choice in the zoo.

\subsection{First flush phenomenon}

The $M(V)$ curves developed of pervious and impervious surface runoff in the zoo are shown in Fig.4. Deviation of the $M(V)$ curve above the bisector is an indicator of first flush. The $M(V)$ curves in Wuhan City Zoo indicate that no first flush existed in pervious surface runoff, but this phenomenon was very clear in impervious surface runoff.

Some researchers considered that the concentration of pollutants in the first flush is positively related to rainfall intensity and percent of impervious area, but negatively related to the watershed area (Lee et al., 2002). Our findings support Lee et al., indicating that the first flush phenomena from the impervious surface runoff in the zoo was caused by intensive rainfall, a highly impervious surface, and the small runoff area.

\section{Conclusions}

In Wuhan City Zoo, a typical urban tourist area, pollutant concentration was positively relationship to flow rate and rainfall intensity in runoff from the pervious surface. However, the impervious surface runoff peaked only initially, reflecting the phenomenon of the first flush. The pollution loads were dominated by the particulate forms of $\mathrm{N}$ and $\mathrm{P}, 61 \%, 78 \%$ of the total, respectively, emphasizing the importance of management strategies that 
target these pollutant forms.

Acknowledgements: The authors gratefully thank Desiree Derrick Tullos for English correction of the manuscript.

\section{References}

APHA-AWWA-WPCF, 1998. Standard methods for the examination of water and wastewater [M]. 20th ed. Washington DC, USA.

Characklis G W, Wiesner M R, 1997. Particulateles, metals, and water quality in runoff from larges urban watershed[J]. J Environ Eng, 123(8): 753-759.

Choe J S, Bang K W, Lee J H, 2002. Characterization of urban runoff in urban areas[J]. Wat Sci Tech, 45(9): 249-254.

Deletic A, 1998. The first flush load of urban surface runoff[J]. Wat Res, 32(8): 2462-2470.

Ebina J, Tsutsui T, Shirai T, 1983. Simultaneous determination of total nitrogen and phosphorus in water using peroxodisulfate oxidation[J]. Wat Res, 17: 1721-1726.

Fraser A I, Harrod T R, Haygarth P M, 1999. The effect of rainfall intensity on soil erosion and particulateulate phosphorus transfer from arable soils[J]. Wat Sci Tech, 39(12): 41-45.

Gromaire-Mertz M C, Garnaud S, Gonzalez A et al., 1999. Characterisation of urban runoff pollution in Paris[J]. Wat Sci Tech, 39: 1-8.

Gupta K, Saul A J, 1996. Specific relationships for the first flush load in combined sewer flows[J]. Wat Res, 30(5): 1244 1252.

Hammad A H A, Borresen T, Haugen L E, 2006. Effects of rain characteristics and terracing on runoff and erosion under the
Mediterranean[J]. Soil Till Res, 87(1): 39-47.

He Q C, Li L Q, Kong L L et al., 2005. Characteristics of storm runoff pollution in hanyang district of Wuhan City[J]. China Water \& Wastewater, 21(2): 101-103.

Lee J H, Bang K W, 2000. Characterization of urban stormwater runoff[J]. Wat Res, 34(6): 1773-1780.

Lee J H, Bang K W, Ketchum L H et al., 2002. First flush analysis of urban storm runoff[J]. Sci Total Environ, 293(1/2/3): $163-175$.

Novotny V, Olem H, 1994. Water quality prevention, identification, and management of Diffuse pollution[M]. New York: Van Nostrand Reinhold.

Sansalone J J, Buchberger S G, 1997. Partitioning and first flush of metals in urban roadway storm water[J]. J Environ Eng, 123(2): 134-143.

Smullen J T, Schallcross A L, Cave K A, 1999. Updating the US nationwide urban runoff quality data base[J]. Wat Sci Tech, 39(12): 9-16.

Taylor G D, Fletcher T D, Wong T H F et al., 2005. Nitrogen composition in urban runoff-implications for stormwater management[J]. Wat Res, 39(10): 1982-1989.

US EPA, 2002. 2000 National water quality inventory[R]. Office of Water, Washington, DC. http://www.epa.gov/305b/ 2000report.

Uunk E J B, Ven F H M, 1987. Water quantity and quality in the new town of Lelystad[M]. In: Effects of land use on fresh water: agriculture, forestry, mineral exploitation, urbanization (Solbe J. F., De L. G., ed.). WRc/Ellis Horwood, Chichester.

Wanielista M P, Yousef Y A, 1993. Stormwater management[M]. NY, USA: John Wiley and Sons, Inc. 